\title{
Phase I Study of Granulocyte Colony-stimulating Factor in Patients with Transitional Cell Carcinoma of the Urothelium
}

\author{
Janice L. Gabrilove, * Ann Jakubowski, ${ }^{*}$ Kathy Fain, ${ }^{*}$ John Grous, * Howard Scher, ${ }^{*}$ Cora Sternberg, * \\ Alan Yagoda," Bayard Clarkson, ${ }^{*}$ Mary Ann Bonilla, ${ }^{*}$ Herbert F. Oettgen," Kirby Alton," \\ Thomas Boone, ${ }^{\ddagger}$ Bruce Altrock, ${ }^{\ddagger}$ Karl Welte, ${ }^{*}$ and Lawrence Souza ${ }^{\ddagger}$ \\ *Department of Medicine, Memorial Sloan-Kettering Cancer Center, New York, New York; Department of Developmental \\ Hematopoiesis and Cytokine Biology, The Sloan-Kettering Institute, New York, New York 10021; \\ and ${ }^{\ddagger}$ Amgen, Inc., Thousand Oaks, California 91320
}

\begin{abstract}
Recombinant human granulocyte colony-stimulating factor (rhG-CSF) was administered at a dose of $1-60 \mu \mathrm{g} / \mathrm{kg}$ of body weight to 22 patients with transitional cell carcinoma before chemotherapy as part of a Phase I/II study. In all patients, a specific dose-dependent increase in the absolute neutrophil count (ANC) of 1.8-12 fold was seen. In addition, this augmentation in the ANC was accompanied by an increase in leukocyte alkaline phosphatase, a marker of secondary granule formation. In six of eight patients analyzed, an increase in bone marrow myeloid to erythroid cell ratio was seen. Day 14 peripheral blood cell derived colony forming unit granulocyte macrophage were also increased by day 6 of rhG-CSF treatment. Circulating levels of eosinophils and basophils were unchanged; however, a 10-fold increase in monocytes was observed in patients treated at the highest doses. There was also a small increase in CD3 + lymphocytes that was not dose dependent. Hemoglobin, hematocrit, and platelet count remained near baseline throughout the period of rhG-CSF administration. These findings demonstrate that rhG-CSF is a potent stimulus for normal neutrophil proliferation and maturation.
\end{abstract}

\section{Introduction}

Human granulocyte colony stimulating factor $(\mathrm{hG}-\mathrm{CSF})^{1}$ has recently been biologically and biochemically characterized and purified $(1,2)$, molecularly cloned (3) and successfully expressed in Escherichia coli (3), as a recombinant protein. This hematopoietic regulator has been shown to promote the proliferation and differentiation of neutrophil granulocytes both in vitro and in vivo (1-7). Furthermore, polymorphonuclear leukocytes from treated animals demonstrate an enhanced ability to reduce nitroblue tetrazolium and respond normally to standard tests for chemotaxis and chemoluminescence (5). Re-

Address reprint requests to Dr. Gabrilove, Department of Medicine, Memorial Sloan-Kettering Cancer Center, New York, NY 10021.

Received for publication 20 January 1988 and in revised form 19 April 1988.

1. Abbreviations used in this paper: ANC, absolute neutrophil count; hG-CSF, human granulocyte colony-stimulating factor; IMDM, Iscove's modified Dulbecco's medium; rhG-CSF, recombinant hGCSF.

J. Clin. Invest.

(C) The American Society for Clinical Investigation, Inc.

$0021-9738 / 88 / 10 / 1454 / 08 \quad \$ 2.00$

Volume 82, October 1988, 1454-1461 cently, we have demonstrated that cynomolgus monkeys treated with either high-dose cytoxan $(60 \mathrm{mg} / \mathrm{kg}$ per $\mathrm{d} \times 2 \mathrm{~d})$ (5), busulfan (8) or in the setting of autologous transplantation (9) have an accelerated recovery of their neutrophil counts after treatment with recombinant hG-CSF (rhG-CSF).

This report represents the complete Phase I results obtained from a Phase I/II clinical trial designed to explore the use of rhG-CSF in cancer patients at risk for chemotherapyinduced neutropenia. In this portion of the study, the objectives were to define the clinical safety, pharmacokinetics, and hematopoietic cell response to rhG-CSF administration.

\section{Methods}

Patients. 22 patients who fulfilled the criteria for the diagnosis of transitional cell cancer of the genitourinary tract were treated with rhG$\mathrm{CSF}$ after giving informed consent. The patients ranged in age from 41 to $77 \mathrm{yr}$ and had a median Karnofsky performance status of 90 (60-100). One patient had received prior systemic chemotherapy $1 \mathrm{yr}$ before entry; four patients had been previously treated with pelvic irradiation for bladder (3) or colon (1) carcinqma 1-8 yr before rhGCSF treatment. Only patients with normal neutrophil $(1,500-8,800 /$ $\mathrm{mm}^{3}$ ) counts were eligible for the study. All patients had normal platelet counts $\left(>100,000 / \mathrm{mm}^{3}\right)$, preserved coagulation function (prothrombin $<14$ seconds; partial thromboplastin time $<35 \mathrm{~s}$ ), normal serum calcium, electrocardiogram, and chest $x$ ray, adequate renal function (blood urea nitrogen $<30 \mathrm{mg} / \mathrm{dl}$; creatinine $<2.0 \mathrm{mg} / \mathrm{dl}$ ), hepatic function (bilirubin $<1.5 \mathrm{mg} / \mathrm{dl}$ ), life expectancy of $6 \mathrm{mo}$ or more and the ability to sign a written consent form. Concomitant treatment with corticosteroids, trimethoprim sulfamethoxazole, chloramphenicol, $\mathrm{H}_{2}$ antagonists, or lithium was not permitted.

Clinical and laboratory monitoring. The following battery of tests was performed before administration of rhG-CSF, on day 6 of rhGCSF administration and before commencing chemotherapy: an electrocardiogram, chest $x$ ray, electrolyte measurements, liver and renal function studies, leukocyte alkaline phosphatase and serum immunoelectrophoresis (10-60 $\mu \mathrm{g} / \mathrm{kg}$ dose level only). Two complete blood counts with white cell differential platelet and reticulocyte counts were obtained (at a similar time of day) on two separate days before rhGCSF treatment and daily when possible for the remainder of the study period. Blood samples were also obtained at the onset and periodically thereafter to test for the presence of neutralizing or nonneutralizing antibodies to rhG-CSF. In consenting patients, a bone marrow aspiration was obtained before and on day 6 of rhG-CSF treatment. Bone marrow aspirations were analyzed for morphology, myeloid/erythroid cell ratio and assayed for day 7 and day 14 colony-forming unit granulocyte-macrophage (CFU-GM) content (see below). Vital signs and physical examinations were performed at regular intervals throughout the study period. In those patients with measurable disease, monitoring for any evidence of tumor growth was performed.

Hematopoietic progenitor cell assay. CFU-GM assays were performed as follows: peripheral blood samples and bone marrow aspi- 
rates were obtained from patients after informed consent. Peripheral blood or bone marrow cells were diluted 1:1 with PBS (without calcium and magnesium) and allowed to sediment. The leukocyte-rich plasma was then collected and subjected to a density cut with FicollHypaque $\left(d=1.077 \mathrm{~g} / \mathrm{cm}^{3}\right.$; Pharmacia Fine Chemicals, Piscataway, $\mathrm{NJ})$. Low density cells were resuspended in Iscove's modified Dulbecco's medium (IMDM). For CFU-GM, $5 \times 10^{4}-1 \times 10^{5}$ cells per milliliter in 0.3\% agar (Difco Laboratories, Detroit, MI) in McCoy's modified assay medium containing $12.5 \%$ FCS were cultured in 35-mm tissue culture dishes (Corning Glassware, Corning, NY) in a $5 \% \mathrm{CO}_{2}$ humidified incubator and scored for colonies and clusters at day 7 and day 14, respectively. Cultures were stimulated by the addition of either 50,500 or $5,000 \mathrm{U}$ of rhG-CSF, rhGM-CSF or $10 \%$ $\mathrm{vol} / \mathrm{vol}$ conditioned medium from the human bladder carcinoma cell line 5637.

Neutrophil function. Mature neutrophils were separated and obtained as a distinct population by subjecting peripheral blood to a discontinuous Percoll gradient (10). Neutrophils recovered from the $75 \%$ layer were adjusted to $10^{6} \mathrm{cells} / \mathrm{ml}$. Chemotaxis was measured using a modification of the method of Boyden (11). Briefly, blind well chambers were filled with zymosan (Sigma Chemical Co., St. Louis, MO) in HBSS, covered with $5-\mu \mathrm{m}$ pore membrane filter (Millipore Corp., Bedford, MA) and the top chamber filled with $2 \times 10^{5}$ neutrophils in BSS containing 2\% BSA (Sigma Chemical Co.). After incubation $\left(3 \mathrm{~h}, 37^{\circ} \mathrm{C}\right)$, the filters were fixed, stained with hematoxylin, and cleared in xylene. The number of neutrophils crossing the filter (lower surface) were counted using a light microscope (400X).

Surface marker analysis. Phenotypic analysis of mononuclear cells isolated from heparinized venous blood by Ficoll-Hypaque gradient density centrifugation were performed before and on day 6 of rhG-CSF treatment. A panel of FITC-conjugated monoclonal antibodies were used including OKT3, OKT4, OKT8, OKT11, OKB (CALLA) (Ortho Pharmaceutical Co., Raritan, NJ); B1, B4, CR11 (Coulter Corp., Hialeah, FL) and Leu 9, anti-Tac, anti-HLA-DR (Becton-Dickinson Co., Mountain View, CA). Antibody reactivity with test cells was determined by direct immunofluorescence. A sample of $10^{6}$ test cells were incubated $\left(4^{\circ} \mathrm{C}\right.$ for $\left.30 \mathrm{~min}\right)$ with $5 \mu \mathrm{l}$ of a given test antibody, washed twice and detected by flow cytometry (FACS IV; Becton-Dickinson).

$r h G-C S F$. The rhG-CSF (Lot $604,0.27 \mathrm{mg} / \mathrm{ml}$ ) used in these studies was produced by recombinant DNA techniques. The hG-CSF gene was isolated and then inserted into and expressed by $E$. coli (3). Recombinant hG-CSF purified from $E$. coli has a molecular weight of 18,800 and is $>95 \%$ pure (3). The recombinant protein formulated in an aqueous buffer contains $<0.06 \mathrm{EU} / \mathrm{ml}$ endotoxin as measured in a limulus amebocyte assay. The specific activity is $\sim 1.0 \times 10^{8} \mathrm{U} / \mathrm{mg}$ of protein as measured in a CFU-GM or thymidine incorporation assay (3).

G-CSF immunoassay. G-CSF levels were quantitated by a solidphase sandwich immunoassay $(12,13)$ using polyclonal rabbit antirhG-CSF, a G-CSF monoclonal antibody and 125 I labeled anti-immunoglobulin (New England Nuclear, Boston, MA) (Chang, D., H. Hockman, and B. Altrock, manuscript in preparation). The sensitivity of the assay employed was $100 \mathrm{pg} / \mathrm{ml}$ and a linear dose response was observed through $0.2 \mu \mathrm{g} / \mathrm{ml}$ in human serum. Serum samples were collected at indicated time points $(0,1,5,10,15,20,40,60,10,120$, $240,360,480,720,960$, and 1,440 min) following rhG-CSF administration, diluted and assayed (at least in triplicate) in parallel with appropriate standards for G-CSF quantitation. Experimental variability in this assay routinely averaged $<5 \%$. Regression analysis of this data using the StatView 512+ (Brainpower, Inc., Calabasas, CA) program allowed slope and, consequently, $t_{1 / 2}$ determination according to conventional methods as described in Shargel and $\mathrm{Yu}$ (14).

Study design. This combined Phase I and II clinical trial was an open label study of both safety and efficacy, with five dosage groups containing three to five patients each. Dose levels included were 1, 3, 10,30 , and $60 \mu \mathrm{g}$ of $\mathrm{rhG}-\mathrm{CSF} / \mathrm{kg} / \mathrm{d}$. Recombinant hG-CSF was administered under supervision in either the inpatient hospital or outpatient clinic at Memorial Sloan-Kettering Cancer Center. Recombinant
hG-CSF was diluted into $50 \mathrm{~cm}^{3}$ of $5 \%$ dextrose in water containing 2 $\mathrm{mg} / \mathrm{ml}$ human serum albumin and administered once daily as a halfhour intravenous infusion. This course of treatment consisted of daily administration of rhG-CSF for a total of $6 \mathrm{~d}$ or until the white blood cell (WBC) count reached 100,000 per cubic millimeter. A patient was removed from participation in this study if significant intolerance to rhG-CSF, noncompliance, a missed visit, or recurrent illness occurred that would affect assessment of clinical status to a significant degree.

\section{Results}

Absolute neutrophil count (ANC). 22 patients were entered onto this study. 21 patients were evaluable for hematopoietic cell changes. The daily ANC from these 21 patients treated with $1-60 \mu \mathrm{g} / \mathrm{kg}$ per $\mathrm{d}$ for $6 \mathrm{~d}$ are depicted in Fig. 1. All patients irrespective of prior therapy, responded to a given dose of rhG-CSF with comparable kinetics and degree of ANC elevation (Fig. 1). In patients receiving $1 \mu \mathrm{g} / \mathrm{kg}$ per $\mathrm{d}$ of $\mathrm{rhG}-\mathrm{CSF}$, a gradual increase in the ANC was noted, with the maximum affect achieved by day 3 of treatment (Fig. 1). In patients receiving 3-30 $\mu \mathrm{g} / \mathrm{kg}$ per $\mathrm{d}$, a rapid elevation in the neutrophil count is seen within the first $24 \mathrm{~h}$ (Fig. 1). This augmentation in neutrophil count plateaued by day 3 and remained consistently elevated throughout the remaining treatment period (Fig. 1). In patients treated with $60 \mu \mathrm{g} \mathrm{rhG}-\mathrm{CSF} / \mathrm{kg}$, a rapid increase in the circulating neutrophil count was also observed after the first day of rhG-CSF administration; however, throughout the course of the subsequent $5 \mathrm{~d}$ of therapy, the neutrophil count continued to rise without attaining a sustained plateau. After discontinuation of rhG-CSF, the total WBC count and the ANC decreased by one-half within the first $48 \mathrm{~h}$. Subsequently, blood counts in patients receiving $1-10 \mu \mathrm{g} / \mathrm{kg}$ per $\mathrm{d}$ returned to within the normal range in $2-4 \mathrm{~d}$. The WBC count in patients who received higher doses of $\mathrm{rhG}$ CSF (30-60 $\mu \mathrm{g} / \mathrm{kg}$ per d) required a longer period (4-7 d) to return to normal values. Patients with a history of prior radiation treatment exhibited the highest baseline neutrophil counts and the highest ANC following rhG-CSF administration; however, the fold increase in ANC observed was similar to that seen in the respective cohort of other patients treated with the same dose of rhG-CSF.

When the average ANC on days 6 and 7 of treatment was compared to the average ANC of the two pretreatment values, a 1.8-12-fold increase in the ANC was noted (Table I). In patients receiving $1-10 \mu \mathrm{g} / \mathrm{kg}$ per $\mathrm{d}$ of $\mathrm{rhG}-\mathrm{CSF}$, this increase in ANC was due to an absolute increase in mature segmented PMN granulocytes with some increase in band forms at the $10-\mu \mathrm{g}$ dose level (Table II). In patients receiving higher doses of rhG-CSF (30-60 $\mu \mathrm{g} / \mathrm{kg}$ per d), the increase in the ANC also included a small percentage of immature neutrophils (Table II). In addition, at doses of $10 \mu \mathrm{g} / \mathrm{kg}$ per $\mathrm{d}$ or more of rhG-CSF, an increase in band forms was initially seen within the first 24 $\mathrm{h}$, concomitant with the initial rise in the circulating ANC (data not shown). Other morphological changes including Döhle bodies, toxic granulations, and decreased nuclear lobulation were observed in neutrophils from rhG-CSF-treated patients. These changes were most prominent in patients receiving the highest doses of rhG-CSF.

Patients' neutrophil function was measured by chemotaxis both before and upon completion of rhG-CSF treatment and compared to values obtained for healthy volunteers. In some of the patients analyzed, a marked increase in spontaneous leukocyte migration was seen before rhG-CSF treatment. This 

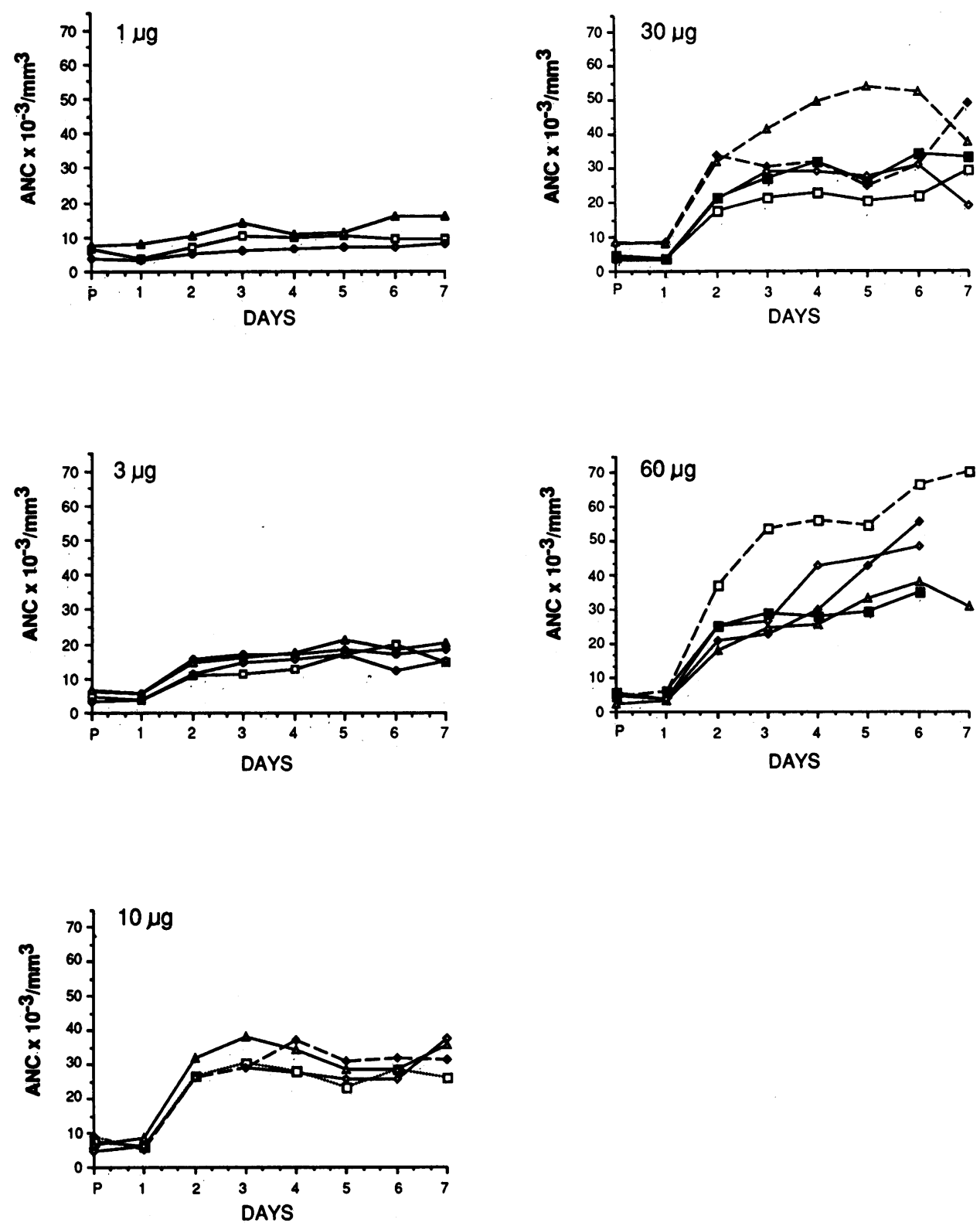

Figure 1. Absolute neutrophil counts (ANC) in patients treated with recombinant human granulocyte colony stimulating factor. ANC in patients having had no prior cancer therapy (-), prior radiation therapy (- - ) and prior chemotherapy (---). Recombinant hG-CSF was administered daily as described in the methods section on days 1 through 6. Baseline ANC values are shown for one pretreatment day $(P)$ and on day 1 before rhG-CSF treatment.

neutrophil migration was not further augmented in the presence of a chemoattractant such as zymosan, suggesting that neutrophils from some of these tumor-bearing patients were already chemokinetically activated. In addition, Mol antigen

Table I. The Range in Absolute Neutrophil Count Increase over Baseline Calculated from the Average Counts Recorded on Days 6 and 7

\begin{tabular}{cc}
\hline Dose & Increase \\
\hline$\mu g / k g$ & \\
1 & $1.8-2.1$ \\
3 & $3.1-4.0$ \\
10 & $3.9-5.7$ \\
30 & $4.7-8.3$ \\
60 & $5.9-12.1$
\end{tabular}

expression, an additional marker of neutrophil activation, appeared to be increased in that same patient population. In other patients, a significant decrease in spontaneous leukocyte migration was noted at baseline. In this instance, neutrophils

Table II. Percent Segmented Neutrophils (S), Band Forms (B), and Immature Myeloid Cells (IM) in the Peripheral Blood before and at the End of Treatment with rhG-CSF

\begin{tabular}{|c|c|c|c|c|c|c|c|}
\hline \multirow[b]{2}{*}{ Dose } & \multirow{2}{*}{$\begin{array}{l}\text { No. of } \\
\text { patients }\end{array}$} & \multicolumn{3}{|c|}{ Pre } & \multicolumn{3}{|c|}{ Post } \\
\hline & & $\mathbf{S}$ & B & IM & $\mathbf{S}$ & B & IM \\
\hline$\mu g / k g$ & & \multicolumn{3}{|c|}{$\%$} & \multicolumn{3}{|c|}{$\%$} \\
\hline 1 & 3 & 100.0 & 0.0 & 0.0 & 100.0 & 0.0 & 0.0 \\
\hline 3 & 4 & $96.9-100$ & $0.0-3.1$ & 0.0 & $82.6-96.8$ & $0.0-17.4$ & $0.0-3.2$ \\
\hline 10 & 4 & $94.7-100$ & $0.0-5.3$ & 0.0 & $69.2-96.5$ & $2.9-29.6$ & $0.6-7.7$ \\
\hline 30 & 5 & $99.4-100$ & $0.0-0.6$ & 0.0 & $69.0-91.8$ & $8.2-29.3$ & $0.0-4.1$ \\
\hline 60 & 5 & $99.3-100$ & $0.0-0.7$ & 0.0 & $60.2-93.9$ & $8.7-30.7$ & $1.2-4.5$ \\
\hline
\end{tabular}


did exhibit enhanced migration in response to zymosan. After rhG-CSF, spontaneous leukocyte migration either normalized or decreased, while enhanced migration in response to a chemoattractant such as zymosan was preserved in this group (data not shown).

Other peripheral blood hematopoietic cell lineages. Eosinophil and basophil granulocytes remained unchanged (data not shown). Monocytes were unchanged in patients treated with lower doses of rhG-CSF (1-10 $\mu \mathrm{g} / \mathrm{kg}$ ); however, a 10-fold increase in monocytes was noted in patients receiving higher doses (30-60 $\mu \mathrm{g} / \mathrm{kg})$. In addition, approximately a twofold increase in the absolute lymphocyte count was noted that was not dose related. Phenotypic marker analysis of peripheral blood mononuclear cells employing a panel of FITC-conjugated monoclonal antibodies including OKT3, OKT4, OKT8, OKT11, TAC (IL-2r), OKB (CALLA), B1, B2, and HLA-DR revealed the majority of the increase could be attributed to OKT3+ (pan T) lymphocytes. Hemoglobin, hematocrit and platelet counts were not significantly changed from baseline at any dose level (Table III).

Bone marrow changes. Bone marrow cellularity and myeloid to erythroid ratio was assessed in 10 patients who agreed to two bone marrow aspirations. In two patients, the samples obtained before administration of rhG-CSF contained no spicules and were not technically adequate for evaluation. In six patients, an increase in the bone marrow myeloid to erythroid cell ratio was observed when compared to pretreatment values (Table IV). In two other patients, no change in the marrow myeloid to erythroid cell ratio was seen. One of these two patients was treated at the lowest dose level of $1 \mu \mathrm{g} / \mathrm{kg}$ per d. Patient 9, who was treated at a dose of $10 \mu \mathrm{g} / \mathrm{kg}$ per d, had previously received pelvic irradiation as part of prior treatment for colorectal carcinoma (Table IV). It is interesting to note that this patient had a pretreatment ratio almost twice that of the other patients.

An estimation of cellularity was assessed by examining the spicules of the marrow and comparing the hematopoietic to fat cell ratio. In three of four patients treated at a dose of 3-10 $\mu \mathrm{g} / \mathrm{kg}$ per $\mathrm{d}$, the increase in marrow cellularity and myeloid elements in particular was primarily due to an increase in the number of mature segmented neutrophil granulocytes present.

Table III. Hemoglobin, Hematocrit, and Platelet Count Values in Patients Treated with rhG-CSF

\begin{tabular}{lcccc}
\hline \multicolumn{1}{c}{ Parameter } & Dose & $\begin{array}{c}\text { No. of } \\
\text { patients }\end{array}$ & Pre $^{*}$ & Treatment $^{*}$ \\
\hline & $\mu g / k g$ & & \multicolumn{2}{c}{ mean $\pm S D$} \\
Hemoglobin & 3 & 4 & $13.4 \pm 2.3$ & $14.0 \pm 3.0$ \\
$(g / d l)$ & 60 & 4 & $14.3 \pm 1.2$ & $13.8 \pm 0.7$ \\
& $1-60$ & 20 & $13.3 \pm 1.6$ & $13.1 \pm 1.7$ \\
& 3 & 4 & $40.4 \pm 7.1$ & $40.6 \pm 8.6$ \\
Hematocrit & 60 & 4 & $43.9 \pm 2.0$ & $43.0 \pm 2.3$ \\
$(\%)$ & $1-60$ & 20 & $40.6 \pm 4.9$ & $40.0 \pm 4.8$ \\
& 3 & 4 & $373 \pm 129$ & $388 \pm 218$ \\
Platelets & 60 & 4 & $331 \pm 149$ & $255 \pm 112$ \\
$\left(\right.$ cells $\left.\times 10^{-3} / \mu l\right)$ & $1-60$ & 20 & $333 \pm 120$ & $329 \pm 159$ \\
\hline
\end{tabular}

* Values determined from the average of two pretreatment days.

${ }^{\ddagger}$ Values determined from the average of days 6 and 7.
Table IV. Myeloid:Erythroid Ratios Determined Both before and on day 6 of Course 1 rhG-CSF Administration

\begin{tabular}{cccc}
\hline & & \multicolumn{2}{c}{ M:E } \\
\cline { 3 - 4 } Patient No. & Dose & Pre & Day 6 \\
\hline & $\mu g / k g$ & & \\
2 & 1 & 2.2 & 2.2 \\
4 & 3 & 2.9 & 7.8 \\
5 & 3 & 2.0 & 6.7 \\
7 & 10 & 3.4 & 12.5 \\
9 & 10 & 6.0 & 5.0 \\
20 & 30 & 1.0 & 5.0 \\
14 & 60 & 1.7 & 5.0 \\
21 & 60 & 3.5 & 19 \\
\hline
\end{tabular}

In two of three evaluable patients treated at a dose of 30-60 $\mu \mathrm{g} / \mathrm{kg}$ per $\mathrm{d}$ this change in cellularity resulted from a marked increase in the proportion of promyelocytic neutrophil granulocytes in addition to an increase in nonsegmented and segmented forms. The granule content of these promyelocytes was also markedly increased.

$C F U-G M$. Bone marrow and peripheral blood CFU-GM were assessed in nine patients before and on the sixth day of rhG-CSF treatment $(\geq 3 \mu \mathrm{g} / \mathrm{kg})$. Circulating CFU-GM were responsive in most cases to growth stimuli provided by either rhGM-CSF (500 U), rhG-CSF (500 U) or $10 \%$ (volume to volume) conditioned medium from the human bladder cell line 5637, which is known to contain GM-CSF as well as IL-1 (Hemopoietin-1) $(15,16)$. There were no peripheral blood CFU-GM detectable before rhG-CSF administration in eight of nine patients. One patient before treatment had circulating CFU-GM, as measured in a 14-d assay (18 colonies with rhGCSF, 8 colonies with rhGM-CSF and 10 colonies with 5637 supernate). On the sixth day of treatment with rhG-CSF, the number of CFU in the peripheral blood rose substantially in all the patients tested (day 7 CFU-GM, 0-29 colonies with rhGCSF, 0-87 colonies with rhGM-CSF and 0-12 colonies with 5637 supernate; day 14 CFU-GM, 0-29 colonies with rhGCSF, 0-26 colonies with rhGM-CSF and 6-31 colonies with 5637 supernate). In contrast, bone marrow-derived day 7 and day 14 CFU were either unchanged (1 $\mu \mathrm{g}$ dose level) or decreased in all but one patient who was treated with $60 \mu \mathrm{g} / \mathrm{kg}$ (data not shown).

Pharmacokinetics. Circulating levels of rhG-CSF were assessed by radioimmunoassay of patient serum samples collected at intervals after administration. A subset of five patients receiving $\mathrm{rhG}-\mathrm{CSF}$ at the $10-60-\mu \mathrm{g} / \mathrm{kg}$ per $\mathrm{d}$ dose levels were studied. For a period of $40 \mathrm{~min}$ immediately after cessation of the rhG-CSF infusion, the levels of rhG-CSF remained relatively constant and proportional to the dosage of material administered. After $\mathbf{4 0} \mathrm{min}$, the serum levels of rhG-CSF decayed logarithmically with time allowing the calculation of elimination kinetics. Fig. 2 depicts results obtained for each patient. Elimination half-lives for patients $9,11,12,13$, and 16 were $3.9,3.9,6.3,6.3$, and $5.0 \mathrm{~h}$, respectively, for an average value of 5.1 plus or minus $0.5 \mathrm{~h}$ (standard error). This value is slightly longer than that previously reported $(3.8 \mathrm{~h})$ for rhGCSF clearance in hamsters (17), probably as a result of species differences. Furthermore, these results indicate that the elimi- 


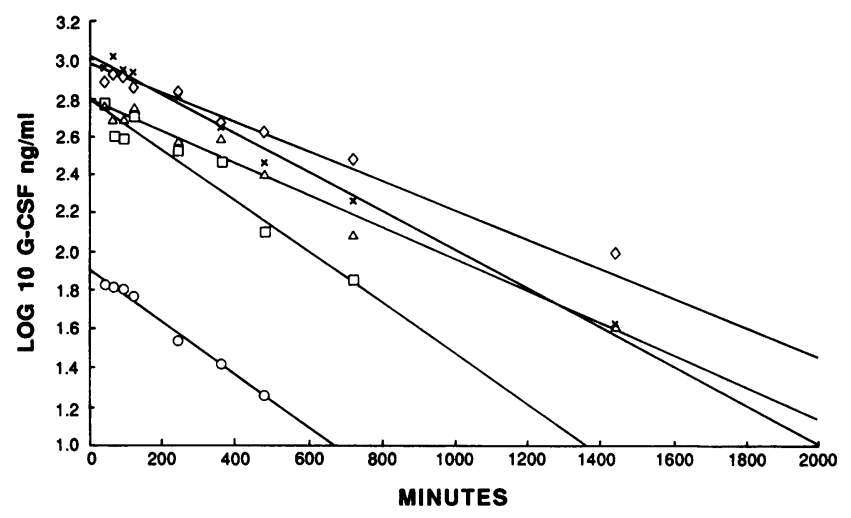

Figure 2. Log-linear regression of G-CSF levels detected by radioimmunoassay in patients sera at time points from 40 to 1440 min postintravenous administration. The data is plotted for patients receiving either $10 \mu \mathrm{g} / \mathrm{kg}$ [patient $9(0)$ ]; $30 \mu \mathrm{g}$ per kilogram [patients $11(\square)$ and $12(\Delta)$ ]; or $60 \mu \mathrm{g}$ per kilogram [patients $13(\diamond)$ and $16(X)$ ]. The slopes of the log linear regression lines were used to recalculate the elimination half-lives.

nation pathway had not reached saturation for the doses tested.

Clinical manifestations. Treatment with rhG-CSF was well tolerated in most patients. Mild to moderate bone "medullary" pain was the only clinical side effect noted in all patients receiving $3 \mu \mathrm{g} / \mathrm{kg}$ per $\mathrm{d}$ or more of $\mathrm{rhG}-\mathrm{CSF}$. This medullary discomfort was characterized as a transient pulsating pain localized primarily to the lower back, posterior iliac crest, and sternum. Sternal discomfort was in most cases elicited only by history and not by direct complaint. This medullary pain in all but three instances was associated only with the infusion, having its onset $\sim 10-15 \mathrm{~min}$ into the infusion of rhG-CSF, in most cases, on day 1 and days 4-6 of treatment. In the three other instances, discomfort also occurred 4-8 $\mathrm{h}$ after rhG-CSF administration. One patient developed more pronounced sternal pain, occurring several hours after rhG-CSF administration. Pulmonary and cardiac evaluation including chest $\mathrm{x}$ ray, cardiogram, and creatinine phosphokinase were unremarkable. The pain resolved after a single dose of diazepam and the patient remained asymptomatic. On the following day, before rhG-CSF administration, a repeat cardiogram revealed trigeminy. Although the patient had a history of trigeminy, it was felt that the evaluation of any treatment-related toxicity would prove difficult. Therefore, a decision was made to discontinue this patient's treatment. In one female postmenopausal patient with mild osteoporosis, medullary pain was associated with diffuse bone pain relieved only by indomethacin. Other side effects associated with the therapeutic use of cytokines and lymphokines $(18,19)$ were not observed. Episodes of sternal discomfort were not found to be associated with any changes in electrocardiograms or cardiac enzymes. No change in physical exam or in tumor-related measurable disease was noted during rhG-CSF treatment. In addition, separate studies have shown no increase in proliferation in either the T24 or 5637 bladder carcinoma cell lines when cultured in the presence versus the absence of rhG-CSF as measured by $\left[{ }^{3} \mathrm{H}\right]$ thymidine incorporation (unpublished results).

Laboratory evaluation revealed a marked increase in the leukocyte alkaline phosphatase (a marker of secondary granule formation in mature myeloid cells), serum alkaline phospha- tase (nonfractionated), without a concomitant increase in either $5^{\prime}$ nucleotidase or gamma glutamal transpeptidase and lactate dehydrogenase (Table V). In addition, a mild increase in serum uric acid was recorded in patients treated at the 30-60- $\mu$ g dose level (Table V). All values returned to normal or near baseline within 1 wk of discontinuing rhG-CSF treatment. No changes in coagulation parameters including prothrombin time, partial thromboplastin and thromboplastin time or fibrinogen were noted. In 2 of 17 evaluable patients, a mild increase in fibrin degradation products was detected during treatment.

\section{Discussion}

We examined the effects of intravenously administered rhGCSF over a dose range of 1 to $60 \mu \mathrm{g} / \mathrm{kg}$ in patients with transitional cell cancer before their receiving combination chemotherapy. The administration of rhG-CSF resulted in a dosedependent increase in the ANC in all patients. In patients receiving a dose of $>10 \mu \mathrm{g} / \mathrm{kg}$ this augmentation of the WBC count was associated with an increase in the appearance of nonsegmented neutrophil granulocytes in the peripheral blood both at $24 \mathrm{~h}$ after the first dose of rhG-CSF and on days 6 and 7 of rhG-CSF. In addition, the elevation in the circulating WBC count was accompanied by an increase in the bone marrow cellularity and myeloid to erythroid cell ratio in all patients receiving 3-60 $\mu \mathrm{g} / \mathrm{kg}$ rhG-CSF, except patient 9 who received $10 \mu \mathrm{g} / \mathrm{kg}$.

Patient 9 had previously been treated with pelvic irradiation. In this individual an augmentation in the myeloid to erythroid cell ratio was observed at baseline. After treatment with rhG-CSF, no further increase in this ratio was recorded. The increased baseline ratio suggests that myeloid cells were already stimulated, perhaps by endogenously produced colony-stimulating factors. We are presently investigating sera from patients who have received prior pelvic irradiation on multiple courses of myeloablative chemotherapy for enhanced G-CSF production. It may be necessary to give patients with increased myeloid to erythroid ratios and/or endogenously

Table V. Changes in Leukocyte Alkaline Phosphatase, Serum Alkaline Phosphatase, Lactate Dehydrogenase, and Uric Acid in Patients Treated with rhG-CSF

\begin{tabular}{|c|c|c|c|c|}
\hline Laboratory parameter & Dose & Baseline & Day 6 & Post \\
\hline & \multicolumn{4}{|l|}{$\mu g / k g$} \\
\hline Leukocyte alkaline & 3 & $34-49$ & $257-372$ & 23-97 \\
\hline $\begin{array}{l}\text { phosphatase } \\
\text { (normal range, } \\
10-90 \text { ) }\end{array}$ & 60 & $38-113$ & $344-392$ & $67-192$ \\
\hline Alkaline phosphatase & 3 & 79-97 & $143-159$ & $72-97$ \\
\hline $\begin{array}{l}\text { (normal range, 30- } \\
115 \mathrm{U} / \mathrm{ml} \text { ) }\end{array}$ & 60 & $45-134$ & $223-374$ & $75-382$ \\
\hline Lactate dehydrogenase & 3 & $140-216$ & 199-301 & $140-180$ \\
\hline $\begin{array}{l}\text { (normal range, 60- } \\
200 \mathrm{U} / \mathrm{liter} \text { ) }\end{array}$ & 60 & $153-180$ & $404-1063$ & $138-206$ \\
\hline Uric acid & 3 & $4.3-9.2$ & $5.9-9.5$ & 4.8-9.4 \\
\hline $\begin{array}{l}\text { (normal range, } 2.5- \\
6.5 \mathrm{mg} / \mathrm{dl} \text { ) }\end{array}$ & 60 & $5.3-6.3$ & $5.3-11.1$ & $4.3-7.6$ \\
\hline
\end{tabular}


elevated G-CSF levels higher doses of rhG-CSF to shorten the duration of neutrophil nadir from myelosuppressive therapy. Indeed, preliminary results from the second phase protocol (where rhG-CSF is administered on days 4 through 11 after initial M-VAC chemotherapy) indicate that four patients having received prior pelvic irradiation had neutrophil nadirs more pronounced than in the majority of patients who had not received any prior cancer therapy (Gabrilove, J., manuscript in preparation).

The changes in the number of neutrophil granulocytes, both in the peripheral blood and bone marrow as well as the evolving left shift seen with higher doses of rhG-CSF, would suggest that granulopoiesis is regulated at more than one level in response to this hormone. At the lowest dose level, the approximate twofold increase in the neutrophil count was not associated with either the appearance of nonsegmented neutrophil granulocytes in the peripheral blood or with any change in the bone marrow myeloid to erythroid cell ratio. This would suggest that the increase in WBC count seen at this dose level was due to either an increase in release of mature neutrophils or to a shift from the marginated to the demarginated pool. The mechanism of this potential shift remains unclear, but is perhaps regulated by an alteration in expression of neutrophil associated cellular adhesion molecules, a property that has recently been described for GM-CSF (20). At higher dose levels, the initial increase seen by $24 \mathrm{~h}$ in the number of peripheral blood nonsegmented and segmented neutrophils suggests a direct or indirect effect of rhG-CSF on both the release of leukocytes from the bone marrow storage compartment as well as on the transit time through the nondividing maturation pool. The appearance of neutrophils containing both Dohle bodies and toxic granulations further implies that the transit time of cells through both the mitotic and nonmitotic compartments was decreased (21). The increase in neutrophil count may also reflect an increase in the half-life of circulating neutrophils, since rhG-CSF appears to increase the survival of neutrophil granulocytes in vitro (22). Finally, the increase in marrow cellularity and myeloid to erythroid cell ratio and specifically, the increase in the percentage of promyelocytes in patients treated with $30-60 \mu \mathrm{g} / \mathrm{kg}$, demonstrates the effect of rhG-CSF on the proliferation of the bone marrow mitotic compartment.

The augmentation of granulopoiesis induced by rhG-CSF administration in vivo in man and the morphological changes noted in circulating neutrophils are similar to that described after the administration of endotoxin (23-26). In mice treated with lipopolysaccharide, G-CSF has been detected in the serum by $3 \mathrm{~h}$ (27). In man, colony-stimulating activity has been described to be increased after administration of endotoxin (28). More recently, we have been able to demonstrate by means of a radioimmunoassay that the serum levels of G-CSF are extremely high in patients treated with Novo-pyrexal, purified preparation of endotoxin (Gabrilove, J., and L. Souza, unpublished observation). It is likely that much of the WBC change seen in the setting of infection are in fact secondary to the effects of endogenously produced G-CSF.

Neutrophil function, as measured by chemotaxis, proved difficult to interpret, given the differences in the state of neutrophil activation before patients received rhG-CSF. Prior studies have suggested that neutrophil migration and activation can be correlated with the extent of disease $(29,30)$. Neu- trophils from patients with early stages of cancer have demonstrated both an increase (30) and a decrease (31) in chemotaxis.

In all but one of eight evaluable patients, bone marrow derived CFU-GM were unchanged or decreased after administration of rhG-CSF. This decrease in CFU-GM per hundred thousand mononuclear cells could reflect: $(a)$ a relative dilution in light of the increase in overall marrow cellularity in these patients, $(b)$ a transient decrease in the size of the CFUGM pool due to cell maturation, and/or (c) a decrease in the transit time of cells through the CFU-GM compartment, causing a decrease in the number of progenitors detected at any given point in time. All three possible explanations may be valid depending on dose, route, and schedule of rhG-CSF administration and time of bone marrow sampling. Finally, the estimation of the real change in marrow CFU-GM content is hampered by the inability to accurately assess the size of the medullary compartment in these patients.

The most consistent effect on hematopoietic progenitors was an increase in the peripheral blood day 14 CFU-GM. Peripheral blood in both normal individuals $(32,33)$ and cancer patients $(34,35)$ contains a variable number of committed myeloid progenitor cells. An increase in these circulating progenitors have been reported in patients with solid tumors as well as acute nonlymphocytic leukemia in early remission, recovering from myeloablative chemotherapy (34, 36). Harvested autologous peripheral blood stem cells, obtained during this postchemotherapy recovery phase, have been employed to achieve hematopoietic reconstitution after intensive chemotherapy or chemoradiotherapy with some success $(37,38)$. One of the major problems with this approach has been the relatively low number of circulating stem cells under normal steady state conditions. The ability to potentially increase the number of autologous peripheral blood progenitors, by pretreating patients with rhG-CSF, would render this approach to transplantation more feasible. The observed increase in peripheral blood CFU-GM seen in our patients suggests a means by which one could facilitate procurement of a sufficient quantity of autologous progenitors to support hematopoietic reconstitution after potentially lethal doses of chemotherapy.

Recombinant hG-CSF was well-tolerated with the exception of mild to moderate medullary pain, associated with the acute administration of rhG-CSF and correlating with the peak serum levels of rhG-CSF achieved. An increase in the serum alkaline phosphatase was also observed that was not hepatic in origin, suggesting a derivation from bone. We are presently investigating this possibility.

This report demonstrates that rhG-CSF is a potent stimulus for normal neutrophil proliferation in man. The potential clinical efficacy of rhG-CSF in the treatment of either iatrogenic (chemotherapy, radiation, bone marrow transplantation) or disease-related (cyclic neutropenia, congenital agranulocytosis, aplastic anemia, lymphoid leukemias) neutropenic disorders is presently under investigation.

\section{Acknowledgments}

The authors wish to express their appreciation to David Chang and Helen Hockman for their expertise in performing radioimmunoassays 
and Michael Downing for his assistance in managing the implementation of the clinical protocol. We would like to thank the Clinical Immunology Nursing Staff for outstanding patient care associated with this study. We also wish to acknowledge the excellent technical assistance of Felecia Kelly, Lorna Barnett, Sue McKenzie and the expert secretarial and artistic assistance of Patricia Korecky, Jeanne Fitzgerald and Julie Heuston in the preparation of this manuscript.

Supported by Amgen, Inc. and by research and clinical grants from the National Cancer Institute (CA-00966, CA-20194, and CA-31780), American Cancer Society (CH-3I), National Institutes of Health (CA-05826 and CA-08748), and the Gar Reichman Foundation.

\section{References}

1. Platzer, E., K. Welte, J. Gabrilove, L. Lu, P. Harris, R. Mertelsmann, and M. A. S. Moore. 1985. Biological activities of human pluripotent hematopoietic colony stimulating factor on normal and leukemic cells. J. Exp. Med. 162:1788-1801.

2. Welte, K., E. Platzer, L. Lu, J. Gabrilove, E. Levi, R. Mertelsmann, and M. A. S. Moore. 1985. Purification and biochemical characterization of human pluripotent hematopoietic colony stimulating factor. Proc. Natl. Acad. Sci. USA. 82:1526-1530.

3. Souza, L. M., T. C. Boone, J. Gabrilove, P. H. Lai, K. M. Zsebo, D. C. Murdock, V. R. Chazin, J. Bruszewski, H. Lu, K. K. Chen, J. Barendt, E. Platzer, M. A. S. Moore, R. Mertelsmann, and K. Welte. 1986. Recombinant human granulocyte colony stimulating factor; effects on normal and leukemic myeloid cells. Science (Wash. DC). 232:61-65.

4. Zsebo, K. M., A. M. Cohen, D. C. Murdock, T. C. Boone, H. Inoue, V. R. Chazin, D. Hines, and L. M. Souza. 1986. Recombinant granulocyte colony stimulating factor: molecular and biological characterization. Immunobiology. 172:175-179.

5. Welte, K., M. A. Bonilla, A. P. Gillio, T. C. Boone, G. K. Potter, J. L. Gabrilove, M. A. S. Moore, R. J. O'Reilly, and L. M. Souza. 1987. Recombinant human granulocyte colony-stimulating factor: effects on hematopoiesis in normal and cyclophosphamide-treated primates. $J$. Exp. Med. 165:941-948.

6. Platzer, E., S. Oez, K. Welte, J. L. Gabrilove, R. Mertelsmann, M. A. S. Moore, and J. R. Kalden. 1986. Human pluripotent hemopoietic colony stimulating factor: activities in human and murine cells. Immunobiology. 172:185-193.

7. Strife, A., C. Lambek, D. Wisniewski, S. Gulati, J. Gasson, D. W. Golde, K. Welte, J. Gabrilove, and B. Clarkson. 1987. Activities of four purified growth factors on highly enriched human hematopoietic progenitor cells. Blood. 69:1508-1523.

8. Welte, K., M. A. Bonilla, A. Gillio, J. L. Gabrilove, G. P. Potter, R. O'Reilly, L. Souza. 1987. In vivo effects of recombinant human G-CSF in therapy induced neutropenias in primates. Exp. Hematol. 15:72.

9. Gillio, A. P., M. A. Bonilla, G. P. Potter, J. L. Gabrilove, R. J. O'Reilly, L. M. Souza, and K. Welte. 1987. Effects of recombinant human granulocyte colony stimulating factor on hematopoietic reconstitution following autologous bone marrow transplantation in primates. Transplant. Proc. 19(Suppl. 7):153.

10. Thomas, E. L., M. B. Grishen, and M. M. Jefferson. 1983. Myeloperoxidase dependent effects of amines on functions of isolated neutrophils. J. Clin. Invest. 72:441-454.

11. Boyden, S. 1962. The chemotactic effect of mixtures of antibody and antigen on polymorphonuclear leukocytes. J. Exp. Med. 115:453-456.

12. Tsu, T. T., and L. A. Hertzenberg. 1980 . Solid phase radioimmunoassays. In Cellular Immunology. B. B. Mishel, S. M. Shiigi, editors. Freeman, San Francisco. 373-397.

13. Eshhar, Z. 1985. Monoclonal antibody strategy and techniques.
In Hybridoma Technology in the Biosciences and Medicine. T. A. Springer, editor. Plenum Publishing Corp., New York. 3-41.

14. Shargel, L., and A. B. C. Yu. 1980. Applied biopharmaceutics and pharmacokinetics. Appleton-Century-Crofts Publishers, Norwalk, CT. 1-251.

15. Gabrilove, J. L., K. Welte, P. Harris, E. Platzer, L. Lu, E. Levi, R. Mertelsmann, and M. A. S. Moore. 1985. Pluripoietin-alpha; a second human hematopoietic colony stimulating factor produced by the human bladder carcinoma cell line 5637. Proc. Natl. Acad. Sci. USA. 83:2478-2482.

16. Warren, D., and M. A. S. Moore. 1987. Interleukin-1 and granulocyte colony stimulating factor synergism: in vivo stimulation of stem cell recovery and hematopoietic regeneration following 5-fluorouracil treatment of mice. Proc. Natl. Acad. Sci. USA. 84:7134-7137.

17. Cohen, A. M., K. M. Zsebo, H. Inoue, D. Hines, T. C. Boone, V. R. Chazin, L. Tsai, T. Ritch, and L. M. Souza. 1987. In vivo stimulation of granulopoiesis by recombinant human granulocyte colony-stimulating factor. Proc. Natl. Acad. Sci. USA. 94:2484-2488.

18. Rosenberg, S. A., M. T. Lotze, L. M. Muul, A. E. Chang, F. P. Avis, S. Leitman, W. M. Linehan, C. N. Robertson, R. E. Lee, J. T. Rubin, C. A. Seipp, C. G. Simpson, and D. E. White. 1987. A progress report on retreatment of 157 patients with advanced cancer using lymphokine activated killer cells and interleukin-2 or high dose interleukin-2 alone. $N$. Engl. J. Med. 316:889-897.

19. Chapman, P., T. Lester, E. Casper, J. L. Gabrilove, G. Wong, S. Kempin, J. Gold, S. Welt, R. Warren, H. Starnes, S. Sherwin, L. Old, and H. F. Oettgen. 1987. Clinical pharmacology of recombinant tumor necrosis factor in patients with advanced cancer. J. Clin. Oncol. 5:1942-1951.

20. Arnaout, M. A., E. A. Want, S. C. Clark, and C. A. Sieff. 1986. Human recombinant granulocyte macrophage colony stimulating factor increases cell to cell adhesion and surface expression of adhesion promoting surface glycoproteins on mature granulocytes. J. Clin. Invest. 78:597-601.

21. Cline, M. 1972. The White Cell. Harvard University Press, Cambridge, MA. 5-70.

22. Begley, C. G., A. F. Lopez, N. A. Nicola, D. J. Warren, M. A. Vadas, C. J. Sanderson, and D. Metcalf. 1986. Purified colony stimulating factors enhance the survival of human neutrophils and eosinophils in vitro: a rapid and sensitive microassay for colony stimulating factors. Blood. 68:162-166.

23. Quesenberry, P., A. Morley, F. Stohlman, K. Rickard, D. Howard, and M. Smith. 1977. Effect of endotoxin on granulopoiesis and colony stimulating factor. $N$. Engl. J. Med. 286:227-232.

24. Mechanic, R. C., E. Frei, M. Landy, and W. W. Smith. 1962. Quantitative studies of human leukocytic and febrile response to single and repeated doses of purified bacterial endotoxin. J. Clin. Invest. 41:162-171.

25. Wolff, S. M., M. Rubenstein, J. H. Mulholland, and D. W. Alling. 1965. Comparison of hematologic and febrile response to endotoxin in man. Blood. 26:190-201.

26. Hartmann, D., M. A. Entringer, M. Vasil, and W. A. Robinson. 1981. The effect of bacterial infection on granulopoiesis (41115). Proc. Soc. Exp. Biol. Med. 167:6-11.

27. Nicola, N., D. Metcalf, M. Matsumoto, and G. Johnson. 1983. Purification of a factor inducing the differentiation of myelomonocytic leukemia cells; identification as granulocyte colony stimulating factor. J. Biol. Chem. 258:9017-9023.

28. Moore, M. A. S., J. L. Gabrilove, and A. P. Sheridan. 1983. Therapeutic implications of serum factors inhibiting proliferation and inducing differentiation of myeloid leukemic cells. Blood Cells. 9:125-137.

29. Sulowicz, W. 1983. Random migration of leukocytes and phagocytic activity of neutrophils in patients with cancer of the gastrointestinal tract at different clinical stages. Rev. Esp. Oncologia. 30:317-321. 
30. Hirano, T. 1984. Changes in polymorphonuclear leukocyte motility under agarose and luminol-dependent chemoluminescence response in patients with gastric cancer. Gastroenterol Jpn. 19:447456.

31. Walter, R. J., and J. R. Danielson. 1985. Defective monocyte and polymorphonuclear leukocyte chemotaxis in patients with epidermoid tumors of the head and neck. Arch. Otolaryngol. 111:538-540.

32. McCredie, K. B., E. M. Hersh, and E. J. Freireich. 1971. Cells capable for colony formation in the peripheral blood of man. Science (Wash. DC). 22:293-294.

33. Chervenick, P. A., and D. R. Boggs. 1971. In vitro growth of granulocytic and mononuclear cell colonies from blood of normal individuals. Blood. 37:131-135.

34. Richman, C. M., R. S. Weiner, and R. A. Yankee. 1976. Increase in circulating stem cells following chemotherapy in man. Blood. 47:1031-1039.
35. Lohrmann, H. P., W. Schreml, T. M. Fleidner, and H. Heimpel. 1979. Reaction of human granulopoiesis to high dose cyclophosphamide therapy. Blut. 38:9-16.

36. To, L. B., D. N. Haylock, R. F. Kimber, and C. A. Juttner. 1984. High levels of circulating hematopoietic stem cells in very early remission from acute non-lymphoblastic leukemia and their collection and cryopreservation. Br. J. Hematol. 58:399-410.

37. Juttner, C. A., L. B. To, D. N. Haylock, A. Branford, and R. J. Kimber. 1985. Circulating autologous stem cells collected in very early remission from acute non-lymphoblastic leukemia produce prompt but incomplete hematopoietic reconstitution after high dose melphalan or supralethal chemo radiotherapy. Br. J. Hematol. 61:739-745.

38. Tilly, H., D. Bastit, J. C. Lucet, H. Esperou, M. Monconduit, and H. Piguet. 1986. Hematopoietic reconstitution after autologous peripheral blood stem cell transplantation in acute leukemia. Lancet. ii:154-156. 